JURNAL KESEHATAN PENA MEDIKA VOL 10 (2) DES 2020

PENA MEDIKA

FAKULTAS ILMU KESEHATAN UNIVERSITAS PEKALONGAN

http://jurnal.unikal.ac.id/index.php/medika ISSN : 2086-843X

\title{
Hubungan Sosialisasi Gizi Dengan Peningkatan Pengetahuan Tentang Pencegahan Obesitas Pada Balita
}

\author{
Vivien Dwi Purnamasari ${ }^{1}$ \\ ${ }^{1)}$ Kesehatan Masyarakat, Institut Ilmu Kesehatan Bhakti Wiyata Kediri \\ ${ }^{\square}$ vivien.purnamasari@iik.ac.id
}

$\begin{array}{ll}\text { ARTICLE INFO : } & \\ \text { Accepted } & : 2020-09-07 \\ \text { Approve } & : \text { 2020-12-22 } \\ \text { Publish } & : 2020-12-27\end{array}$

\begin{abstract}
Currently over nutrition and obesity are epidemics in developed countries, such as UK, Brazil, Singapore and are rapidly developing. The World Health Organization (WHO) noted, in 2005, globally there were about 1.6 billion adults who were overweight or overweight and 400 million of them were categorized as obese. In 2015, it is predicted that obesity cases will double from that number. This study aims to determine the increase in public knowledge about obesity in toddlers. This study used a quasi experimental design with one group pretest and posttest designs. Data collection began on January 9, 2020 in Sumberasih Village, Kediri Regency, with 35 respondents attending the posyandu activities. Of the 35 respondents, it was found that most of the mothers aged 26-30 were 12 respondents, 19 respondents had graduated from high school / MA and 14 respondents did not work. Most of the mother's level of knowledge at the pre-test was in the poor category as many as 13 respondents, while at the time of the post-test with the good category it was 23 people (65.7\%). There is a relationship between the socialization of nutrition and increased knowledge about the prevention of obesity under five.
\end{abstract}

Keyword: Education, level of knowledge, obesity

\begin{abstract}
ABSTRAK
Saat ini gizi lebih dan obesitas merupakan epidemik di negara maju, seperti Inggris, Brasil, Singapura dan dengan cepat berkembang. Organisasi Kesehatan Dunia (WHO) mencatat, pada tahun 2005, secara global ada sekitar 1,6 miliar orang dewasa yang kelebihan berat badan atau overweight dan 400 juta di antaranya dikategorikan obesitas. Pada Tahun 2015 diprediksi kasus obesitas akan meningkat dua kali lipat dari angka itu. Penelitian ini bertujuan untuk mengetahui peningkatan pengetahuan masyarakat tentang obesitas pada balita. Penelitian ini menggunakan desain quasi experiment dengan rancangan one group pretest dan posttest. Pengumpulan data mulai dilakukan pada 9 Januari 2020 di Desa Sumberasih Kabupaten Kediri dengan 35 responden yang hadir pada kegiatan posyandu. Dari 35 responden diperoleh hasil bahwa sebagian besar ibu
\end{abstract}


berusia 26-30 sebanyak 12 responden, berpendidikan dengan tamat SLTA/MA sebanyak 19 responden dan tidak bekerja sebanyak 14 responden. Sebagian besar tingkat pengetahuan ibu pada saat pre test dengan kategori kurang sebanyak 13 responden, sedangkan pada saat post tes dengan kategori baik sebesar 23 orang $(65,7 \%)$. Terdapat hubungan sosialisasi gizi dengan peningkatan pengetahuan tentang pencegahaan obesitas balita.

Kata Kunci: Edukasi, Tingkat Pengetahuan, Obesitas

\section{PENDAHULUAN}

Obesitas merupakan suatu keadaan fisiologis akibat dari penimbunan lemak secara berlebihan di dalam tubuh. Saat ini gizi lebih dan obesitas merupakan epidemik di negara maju, seperti Inggris, Brasil, Singapura dan dengan cepat berkembang di negara berkembang, terutama populasi kepulauan Pasifik dan negara Asia tertentu. Prevalensi obesitas meningkat secara signifikan dalam beberapa dekade terakhir dan dianggap oleh banyak orang sebagai masalah kesehatan masyarakat yang utama (Bilaver, 2009).

WHO menyatakan bahwa obesitas telah menjadi masalah dunia. Data yang dikumpulkan dari seluruh dunia memperlihatkan bahwa terjadi peningkatan prevalensi overweight dan obesitas pada 10-15 tahun terakhir, saat ini diperkirakan sebanyak lebih dari 100 juta penduduk dunia menderita obesitas. Angka ini akan semakin meningkat dengan cepat. Jika keadaan ini terus berlanjut maka pada tahun 2230 diperkirakan $100 \%$ penduduk dunia akan menjadi obes (Sayoga dalam Rahmawaty, 2004). Panama dan Kuwait tercatat sebagai dua negara dengan prevalensi obesitas tertinggi di dunia, yakni sekitar 37\%. Setelah itu Peru (32\%) dan Amerika Serikat (31\%). Di Brasil, kenaikan kasus obesitas terjadi pada anakanak sebesar $239 \%$.

\section{Organisasi Kesehatan Dunia (WHO)} mencatat, pada tahun 2005, secara global ada sekitar 1,6 miliar orang dewasa yang kelebihan berat badan atau overweight dan 400 juta di antaranya dikategorikan obesitas. Pada Tahun 2015 diprediksi kasus obesitas akan meningkat dua kali lipat dari angka itu. Obesitas di Indonesia sudah mulai dirasakan secara nasional dengan semakin meningginya angka kejadiannya. Selama ini, kegemukan di Indonesia belum menjadi sorotan karena masih disibukkan masalah anak yang kekurangan gizi. Meskipun obesitas di 
Indonesia belum mendapat perhatian khusus, namun kini sudah saatnya Indonesia mulai melirik masalah obesitas pada anak. Jika dibiarkan, akan mengganggu sumber daya manusia (SDM) di kemudian hari. Prevalensi obesitas di Indonesia mengalami peningkatan mencapai tingkat yang membahayakan. Berdasarkan data SUSENAS tahun 2004 prevalensi obesitas pada anak telah mencapai $11 \%$. Di Indonesia hingga tahun 2005 prevalensi gizi baik 68,48\%, gizi kurang 28\%, gizi buruk $88 \%$, dan gizi lebih 3,4\% (Data SUSENAS,2005).

Berdasarkan data dari Dinas Kesehatan Kabupaten Kediri, kejadian obesitas tertinggi terjadi di cakupan wilayah Puskesmas Sidomulyo yaitu sebanyak 737 kasus, hal ini selaras dengan data 10 trend penyakit yang ada di Puskesmas Sidomulyo untuk kejadian obesitas menduduki peringkat kedua setelah kejadian Hipertensi. Instansi ini sebagai pelengkap data yang kami butuhkan untuk menerapkan intervensi guna menekan angka obesitas.

Berdasarkan uraian tersebut maka dibutuhkan sosialisasi gizi dalam meningkatkan pengetahuan masyarakat dalam pencegahan kasus obesitas yang terjadi pada balita. Hal itu berdasarkan data di wilayah kerja Puskesmas
Sidomulyo ditemukan balita mempunyai berat badan lebih dari $30 \mathrm{~kg}$ sebanyak 3 orang.

\section{METODE PENELITIAN}

Penelitian ini menggunakan desain quasi experiment dengan rancangan one group pretest dan posttest. Peneliti sudah melakukan observasi pertama pretest sehingga peneliti dapat mengetahui perubahan yang terjadi setelah diberikan intervensi dan kemudian dilakukan postest Pengumpulan data mulai dilakukan pada 9 Januari 2020 di Desa Sumberasih Kabupaten Kediri dengan 35 responden yang hadir pada kegiatan posyandu. Responden penelitian adalah Ibu balita yang mengantarkan anaknya untuk periksa ke posyandu. Sampel diambil secara accidental sampling.. Instrumen yang digunakan yaitu dengan kuesioner yang berisi 7 pertanyaan berupa pilihan jawaban benar dan salah. Setiap bagian dibuat skoring dan dianalisis menggunakan uji Wilcoxon.

\section{HASIL}

Berdasarkan hasil survei 35 responden diperoleh karakteristik ibu balita berdasarkan usia, pendidikan tinggi dan pekerjaan yaitu tertera pada tabel 1 sebagai berikut: 
Tabel 1 Distribusi Karakteristik Responden

\begin{tabular}{lcc}
\hline Karakteristik Responden & Frekuensi (n) & Persentase $(\%)$ \\
\hline Usia Ibu & 7 & 20 \\
$20-25$ & 12 & 34 \\
$26-30$ & 9 & 26 \\
$30-35$ & 7 & 20 \\
$>35$ & & \\
Pendidikan Tinggi Ibu & 8 & 23 \\
Tamat SLTP/MTS & 19 & 54 \\
Tamat SLTA/MA & 3 & 9 \\
Tamat D1/D2/D3 & 5 & 14 \\
Tamat PT & & \\
Pekerjaan Ibu & 14 & 40 \\
Tidak bekerja & 4 & 11 \\
PNS & 11 & 32 \\
Wiraswasta & 6 & 17 \\
Pegawai swasta & \multicolumn{2}{c}{} \\
\hline (Sumber : Data Primer 2020$)$
\end{tabular}

(Sumber : Data Primer, 2020)

Berdasarkan tabel 1 menunjukkan bahwa sebagian besar ibu berusia 26-30 sebanyak 12 responden (34\%), berpendidikan dengan tamat SLTA/MA sebanyak 19 responden (54\%) dan tidak bekerja sebanyak 14 responden $(40 \%)$

Tingkat pengetahuan sebelum dan sesudah pemberian sosialisasi gizi pada ibu balita disajikan dalam tabel 2 sebagai berikut:

Tabel 2 Distribusi Frekuensi Tingkat Pengetahuan Responden

\begin{tabular}{lcccc}
\hline \multirow{2}{*}{ Tingkat Pengetahuan } & \multicolumn{2}{c}{ Pre-Test } & \multicolumn{2}{c}{ Post-Test } \\
\cline { 2 - 5 } & $\begin{array}{c}\text { Frekuensi } \\
(\mathbf{n})\end{array}$ & $\begin{array}{c}\text { Persentase } \\
(\boldsymbol{\%})\end{array}$ & $\begin{array}{c}\text { Frekuensi } \\
(\mathbf{n})\end{array}$ & $\begin{array}{c}\text { Persentase } \\
(\boldsymbol{\%})\end{array}$ \\
\hline Baik & 12 & 34,3 & 23 & 65,7 \\
Cukup & 10 & 28,6 & 11 & 31,4 \\
Kurang & 13 & 37,1 & 1 & 2,9 \\
\hline Total & 35 & 100 & 35 & 100 \\
\hline Sumber: Data Primer, 2020) & & & &
\end{tabular}

Berdasarkan tabel 2 menunjukkan pengetahuan dengan kategori baik sebesar sebagian besar tingkat pengetahuan ibu 23 orang $(65,7 \%)$. Ada peningkatan pada saat pre test memiliki tingkat pengetahuan ibu sebelum dan sesudah pengetahuan dengan kategori kurang diberikan sosialisasi gizi dalam mencegah sebanyak 13 responden (37,1\%),sedangkan obesitas pada balita : pada saat post tes memiliki tingkat

Tabel 3 Uji Statistik Perbedaan Tingkat Pengetahuan Pre dan Post Test

\begin{tabular}{ccccc}
\hline Variabel & Mean & p & A & Keputusan \\
\hline Pre Test & 53,60 & 0,037 & 0,05 & $\mathrm{H}_{0}$ ditolak \\
Post Test & 84,8 & $0,8)$ &
\end{tabular}

(Sumber: Data Primer Terolah, 2020) 
Berdasarkan tabel 3 menunjukkan uji bivariat dengan menggunakan uji Wilcoxon yang menunjukkan nilai $\mathrm{p}=0,037$ dan $\mathrm{p}<0,05$ artinya terdapat hubungan sosialisasi gizi dengan peningkatan pengetahuan tentang pencegahan obesitas pada Balita.

\section{PEMBAHASAN}

Penyebab mendasar terjadinya kegemukan dan obesitas adalah ketidak seimbangan energi antara energi yang masuk dan energi yang keluar. Energi yang masuk adalah jumlah energi berupa kalori yang di dapatkan dari makanan dan minuman. Sedangkan energi yang keluar adalah jumlah energi atau kalori yang digunakan tubuh dalam hal seperti bernapas, digesti dan juga melakukan kegiatan fisik (Aini, 2012).

Pada penelitian ini menunjukkan bahwa terdapat hubungan sosialisasi gizi dengan peningkatan pengetahuan tentang pencegahan obesitas pada balita di Desa Sumberasih Kecamatan Wates Kabupaten Kediri. Asupan energi dan pengeluaran energi dipengaruhi oleh berbagai faktor yang dapat dikelompokan menjadi lebih spesifik seperti faktor dari individu berupa genetik dan proses metabolisme tubuh, faktor dari perilaku hidup seperti kurangnya beraktifitas fisik dan faktor dari luar termasuk faktor lingkungan seperti murahnya harga suatu makanan (Kaestner, 2009). Secara umum obesitas terjadi akibat meningkatnya asupan makanan yang tinggi lemak dan kurangnya aktifitas fisik seharihari baik dalam bekerja maupun bertransportasi (WHO, 2015).

Obesitas pada anak-anak terjadi ketika berat badan mereka jauh melebihi berat normal berdasarkan tinggi badan. Kondisi ini berbahaya karena membuat mereka berisiko tinggi mengidap penyakit kronis dan mengalami stres. Obesitas yang terjadi pada masa anak-anak dapat beresiko tinggi untuk menjadi obesitas pada masa dewasanya nanti. Masa anak-anak adalah masa pertumbuhan dan perkembangan sehingga kegemukan pada masa anak menyebabkan semakin banyaknya jumlah sel otot dan tulang rangka sedangkan obesitas pada orang dewasa hanya terjadi pembesaran sel-sel saja sehingga kemungkinan penurunan berat badan ke normal akan lebih mudah. Anak yang mengalami obesitas pada masanya $75 \%$ akan menderita obesitas pula pada masa dewasanya dan berpotensi mengalami berbagai penyebab kesakitan dan kematian antara lain penyakit kardiovaskular dan diabetes mellitus dan akibat yang ditimbulkan obesitas ini akan mempunyai dampak terhadap tumbuh kembang anak 
itu sendiri (Agoes, 2013). Penelitian ini sejalan dengan penelitian yang dilakukan oleh Ayu (2015) yang menyatakan bahwa obesitas yang terjadi pada anak-anak dapat mengganggu pertumbuhan dan perkembangan dan dapat menimbulkan beberapa penyakit seperti penyakit kardiovaskuler dan diabetes mellitus.

Obesitas masih merupakan masalah kesehatan bagi anak maupun dewasa, oleh karena komplikasi jangka pendek obesitas itu sendiri berakibat terhadap pertumbuhan tulang, penyakit endokrin, kardiovaskular dan sistem gastrointestinal (Sjarif, 2004). Pengetahuan adalah merupakan hasil "tahu" dan ini terjadi setelah orang melakukan pengindraan terhadap suatu objek tertentu. Pengindraan terjadi melalui panca indra manusia, yakni indra penglihatan, pendengaran, penciuman, rasa dan raba. Sebagian besar pengetahuan manusia diperoleh melalui mata dan telinga (Notoadmojo,2012)

Pengetahuan sebagai salah satu dari tiga komponen yang mempengaruhi perilaku manusia karena pengetahuan adalah hasil dari obyek tertentu dan sebagian besar pengetahuan manusia diperoleh melalui indera mata dan telinga. Pendidikan kesehatan merupakan salah satu proses untuk meningkatkan pengetahuan seseorang, pengetahuan dapat meningkat karena informasi dari orang lain, media massa elektronik seperti Koran, leaflet, majalah, televise dan radio (Notoadmojo, 2012). Pengetahuan ibu balita diukur dengan mengisi kuesioner dengan 7 item pada pre test dan post test. Diperoleh ada peningkatan pengetahuan sebelum dan sesudah diberikan ( gizi pada ibu balita. Penelitian ini sejalan dengan penelitian yang dilakukan oleh Ikbal (2011) yang menyatakan bahwa ada peningkatan pengetahuan akibat edukasi gizi remaja kelebihan berat badan/obesitas dengan nilai $\mathrm{p}=0,000$ dan untuk kelompok kontrol dengan $\mathrm{p}=0,012$.

Penelitian lain dari Muis, dkk (2014) juga menyampaikan bahwa dengan memberikan edukasi gizi dapat meningkatkan pengetahuan tentang gizi anak SD. Tujuan dari sosialisasi gizi berdasarkan pendekatan sebaran informasi cukup sederhana yaitu memberikan informasi yang masyarakat butuhkan tentang makanan dan zat-zat gizi yang mereka perlukan dan bagaimana makan yang baik. Masyarakat dipandang sebagai orang yang cerdas dan tidak perlu diberitahu apa yang harus dilakukan (Contento IR, 2006).

\section{KESIMPULAN}

Berdasarkan hasil penelitian maka dapat disimpulkan terdapat hubungan sosialisasi gizi dengan peningkatan pengetahuan 
tentang pencegahaan obesitas balita yaitu $\mathrm{p}=0,037$.

\section{SARAN}

Diharapkan dapat meningkatkan peran posyandu dalam peningkatan pemberian sosialisasi gizi seimbang dalam pencegahan obesitas balita di masyarakat.

\section{DAFTAR PUSTAKA}

Agoes, S., \& Poppy, M.2013. Mencegah dan Mengatasi Kegemukan Pada Balita. Jakarta: Puspa Swara

Aini, S.N.2012. Faktor Risiko yang Berhubungan dengan Kejadian Gizi Lebih pada Remaja di Perkotaan. Unnes Journal of Public Health. 1(2) : 2-8

Badan Pusat Statistk Jakarta Pusat.2005. Pedoman Pendataan Survei Penduduk Antar Sensus 2005. Jakarta Pusat: Badan Pusat Statistik

Bilaver, Lucy A.2009. The Causal of Family Income on Childhood Obesity. Health Economics Workshop May 14, 2009.

Contento, I.R.2006. Nutrition Education Linking Research Teory $n$ Practice. Johne\&Barletts

Publishers,Sudbury.P.1-21

Mahdali, Ikbal.2011.Edukasi Gizi Terhadap Perubahan Pengetahuan, Sikap, Pola Konsumsi Dan Aktifitas
Sedentary Remaja Obesitas. Universitas Gorontalo

Muis, dkk. 2014. Pengaruh Pendidikan Gizi Terhadap Pengetahuan dan Sikap Tentang Gizi Anak Sekolah Dasar. Jurnal Gizi Indonesia

Notoatmodjo, Soekidjo. 2010. Metodologi Penelitian Kesehatan. Jakarta: PT Rineka Cipta

Notoatmodjo, Soekidjo, 2012. Promosi Kesehatan dan Ilmu Perilaku. Jakarta: PT Rineka Cipta

WHO.2015. World Health Statistics 2015: World Health Organization

Sayoga, Ibnu Budi.2014. Hubungan Pola Makan, Genetik Dan Kebiasaan Olahraga Dengan Kejadian Overweight pada Mahasiswa Keperawatan S1 di Universitas Muhammadiyah Purwokerto.

Sjarif D. 2004. Anak gemuk, apakah sehat? Jakarta: Divisi anak dan penyakit metabolic. Fakultas Kedokteran Universitas Indonesia; 2004 